\title{
Conspicuous Compassion and Wicked Problems
}

\section{The Howard Government's National Emergency in Indigenous Affairs}

\section{Boyd Hunter ${ }^{1}$}

\begin{abstract}
A 'wicked problem' is a term used in the planning literature to characterise a complex multi-dimensional problem. The article argues that Indigenous child abuse is one such problem. Whatever the merits of the recent federal intervention into Northern Territory Indigenous communities, it is unlikely to succeed without both long-term bipartisan commitment of substantial resources and a meaningful process of consultation with Indigenous peoples. If we are to learn from what policies worked (and what did not work), then it is particularly important that a transparent evaluation framework be established before undertaking policy initiatives.
\end{abstract}

The dramatic press conference of the Prime Minister, John Howard, and the Indigenous Affairs Minister, Mal Brough, on 21 June 2007 produced a front-page headline in the next day's issue of the NT News: 'Martial Law - Howard mobilises cops, military as he declares "national emergency" in NT communities' (Adlam \& Gartrell 2007).

After intense and heated public debate over the 'national emergency' - and clarification of the more controversial proposals (for example, compulsory health checks were to be less invasive than had been feared) - three Bills were introduced to the federal parliament on 7 August 2007, comprising 480 pages of legislation relating to alcohol restrictions, pornography bans, changes to the permit system and township leasing, and to the quarantining of welfare payments.

The Northern Territory National Emergency Response Bill 2007 provided a legislative framework for:

- alcohol restrictions to stem the instances of family violence and sexual abuse of children;

- computer audits to detect prohibited pornographic material;

- five-year leases to better manage investments to improve living conditions in townships;

- land-tenure changes to enable town camps to become normal suburbs;

1 Boyd Hunter is a Fellow at the Centre for Aboriginal Economic Policy Research at The Australian National University. 
- the appointment of government business managers in Aboriginal townships to manage and implement the emergency measures;

- the removal of customary laws as a mitigating factor for bail and sentencing conditions; and

- better management of community stores to deliver healthier and more affordable food to Indigenous families.

The second piece of legislation, The Social Security and Other Legislation Amendment (Welfare Payment Reform) Bill 2007, combined three elements: welfare reform specific to the Northern Territory (NT); welfare reform specific to Cape York; and a broader welfare-reform package announced a little earlier. The government proposed to quarantine various income-support payments and direct Indigenous families to provide basic necessities such as food, clothing and shelter for their children, rather than supporting substance abuse and gambling.

The third and final piece of legislation is the Families, Community Services and Indigenous Affairs and Other Legislation Amendment (Northern Territory National Emergency Response and Other Measures) Bill 2007, which amends existing legislation to include the imposition of bans on pornography and changes to the permit system. Rather than the total scrapping of the permit system in all NT Indigenous communities, as had been proposed in the original press conference, the Bill only lifts the requirement for permits to visit Aboriginal land in townships and access roads and airstrips.

These Bills were passed without substantial amendment on 16 August, after a one-day review hearing in the Senate.

\section{Wicked Problems and Indigenous Policy}

The 'wicked problem' here does not refer to a moralising condemnation of the inherent evil of the widespread child abuse; rather, it is a term used in the planning literature to characterise a complex multi-dimensional problem. Indigenous policy is one of most complex areas facing governments, as it involves many issues that do not exist for other Australians: a dynamic cultural life; a need to change social norms; unique forms of property rights, such as native title; and the intergenerational transmission of disadvantage, sometimes arising from problematic historical government interventions (such as, the 'stolen generation').

The concept of 'wicked problems' was originally proposed by Rittel and Webber (1973). Ill-defined design and planning problems were called 'wicked' because they are often messy, circular, aggressive and intrinsically complex. Rittel and Webber contrast such problems to the relatively 'tame' problems of mathematics, chess or puzzle-solving. Wicked problems have incomplete, contradictory and changing requirements; and solutions to them are often difficult to recognise as such because of complex interdependencies. The solution 
of one aspect of a wicked problem may reveal or create another, even more complex, problem. A wicked problem is likely to be one whose solution requires large groups of individuals to change their mindsets and behaviours.

Conklin (2003) argues that there are four defining characteristics of wicked problems:

1. The problem is not understood until after a solution has been formulated.

2. Stakeholders have radically different world views and different frames for understanding the problem.

3. Constraints and resources for solving the problem change over time.

4. The problem is never solved (completely).

Indigenous policy is easily characterised as a wicked problem. Obviously, mainstream Australian society has a different perspective on the problem from Indigenous stakeholders, who are more likely to emphasise land rights, cultural difference and injustice. One of the main debates for the NT intervention is whether the trade-off between Indigenous rights and socioeconomic status is being taken into account. The existence of this trade-off means Indigenous Australians must 'own' both the problem and solution (Henry 2007). If behavioural and attitudinal change is required, then an adequate process of consultation with Indigenous people is obviously crucial to securing their cooperation. Imposing solutions from above is both profoundly illiberal and unlikely to produce real solutions at all.

Further, the constraints of the problem are changing over time as community dysfunction, sometimes fuelled by excessive alcohol consumption, enters a negative or vicious cycle (see Hunter $2007 \mathrm{~b}$ for a discussion of a related model of cumulative causation).

Finally, the issues involved are extremely unlikely to be resolved completely as the 'modernisation project' is partially, if not wholly, inconsistent with cultural maintenance.

\section{Context to NT intervention}

The immediate rationale for the NT intervention was Ampe Akelyernemane Meke Mekarle ('Little Children are Sacred'), the Report of the Northern Territory Board of Inquiry into the Protection of Aboriginal Children from Sexual Abuse, which 'distressed' the Prime Minister and other readers. However, there have been numerous other reports into child abuse, neglect and violence in Indigenous communities written over many years (see, for example, Martin 1988; Memmott et al. 2001). While the rates of child abuse are higher among all disadvantaged groups compared to the Australian average, it is particularly high in Indigenous communities (Australian Institute of Health and Welfare (AIHW) 2006: Table 2.8). Victoria has the highest number of Indigenous child-abuse substantiations 
per 1000 children (63.0), followed by the ACT (56.0), South Australia (43.20) and NSW (27.1). The NT had a relatively low rate of Indigenous child-abuse substantiations of 13.7 per 1000 children - only Western Australia (12.2) and Tasmania (5.8) had lower rates. It should be noted that child-abuse data may be particularly prone to measurement error as it involves an inherently difficult and sensitive subject matter. However, it should be noted that under-reporting of child abuse is not confined to either Indigenous communities or the NT indeed, the 'Little Children are Sacred' report specifically rejects the notion that Aboriginal culture is the reason for the under-reporting of abuse (Wild \& Anderson 2007: p.58).

Peter Botsman argues that there is a need to put Indigenous child abuse into perspective (2007). Indeed, the fact that substantiated child abuse among non-Indigenous families in Queensland (13.7 per 1000) is as high as that which provoked the NT intervention means that the problem is not confined to Indigenous communities. Given the high level of disadvantage and poverty identified in NT Indigenous communities, the level of substantiated child abuse is relatively low. Obviously, policy needs to address broader issues, rather than simply focusing on Indigenous-specific issues such as permits and land rights.

Some aspects of the intervention were foreshadowed and informed by the Cape York Institute report (CYI 2007) — for example, the focus on quarantining welfare payments for certain behaviour; addressing incentives to work in mainstream jobs; and the reform of the Community Development Employment Projects (CDEP) scheme, the long-standing Indigenous work-for-the-dole program. Nevertheless, the government's plan differed from the CYI report in crucial ways. The CYI report was based more on 'ground-up' theory: it involved substantial collaboration with the Indigenous community and incorporated the direct involvement of community representatives in the proposed Family Responsibility Community (FRC). Another difference was the fact that the quarantining of welfare suggested by the CYI report was not necessarily mandatory.

It became clear in the days following 21 June that there had been no consultations with state and territory governments or local Indigenous community elders. The lack of communication with Indigenous representatives is largely a result of the abolition of ATSIC, as there is no longer any recognised local Indigenous authority for governments to talk to. Even Noel Pearson was given only 15 minutes' warning of the government's planned intervention (Pearson 2007).

The public debate that followed involved heated exchanges between the protagonists. In a sense, this is understandable since the intervention was hastily conceived and sketchily outlined: apart from the occasional press release, there was little to tell people what the government's response actually entailed. Teams 
of bureaucrats and army personnel were sent into the NT to scope the issues involved.

The heat of the public debate has scared off many people who may have had positive contributions to make. ${ }^{2}$ Critics of the NT intervention run the risk of being construed as supporting child abuse by default. However, if policy interventions are misconceived and poorly designed, then the possibility of constructing a truly effective long-term response to child abuse may be compromised by restricting public debate to highly committed people and organisations. The following sections outline the main criticisms of the intervention.

\section{War, Shame and Conspicuous Compassion}

Since 2000, the government has gradually shifted its rhetoric in Indigenous affairs to focus on a more radical agenda. During the life of the Howard government, the analogy of war has been used routinely to describe complex social issues (Hunter 2006). First, there were the 'history wars', as Henry Reynolds, Keith Windschuttle and others fought over the technical detail and interpretation of Australia's colonial history. This is arguably one manifestation of the 'culture wars'. Then came the 'war on terror', following the events of 11 September 2001. Another alleged battleground is the 'poverty war'. Given the involvement of the military and the strident language of the protagonists, it is not too much of a stretch to characterise the intervention in the NT as a 'war on Indigenous child abuse'.

While the analogy of war provides good 'copy' for the media, and hence has utility for politicians, it is a singularly inappropriate term for constructing a positive and informed debate about complex social issues. If Indigenous child abuse and community dysfunction are wicked problems, then the oversimplification of the issues diminishes our capacity to construct effective policy options.

If one is serious about Indigenous policy, one needs to attempt to build a long-term consensus rather than construct a heroic-style conflict between competing policies - where one policy is invariably portrayed as a failure and the other as the solution.

Sanders (2007) demonstrates how the language of failure has become increasingly used to describe Indigenous affairs since 2004. The Howard government has used the idea of past policy failure to introduce major new

\footnotetext{
2 There is some anecdotal evidence of this - a colleague recently presented a paper at a conference on 'Measuring and evaluating Indigenous service delivery' (held in Alice Springs, 25-26 July 2007). Attendees included federal, state and territory and local government staff, personnel from Indigenous organisations, researchers and others. Despite the direct relationship between the theme of the conference and the ongoing events in the NT, there was barely a mention of the national emergency by any of the speakers (personal communication: David Martin, 6 August 2007).
} 
organisational arrangements in Indigenous affairs: the Aboriginal and Torres Strait Islander Commission (ATSIC) was abolished and its programs were re-assigned to 'mainstream' Commonwealth departments.

Is it possible that the claims that anyone who criticises the earnest attempt to address child abuse is a 'nay-sayer' or, worse, supports child abuse by default, have left people morally conflicted and afraid to contribute to the public debate? The over-simplification of the issues has led to an extremity of language and arguments that militates against a reasoned analysis of evaluation of the policy options.

Helen Hughes' recent book, Lands of Shame, makes a direct appeal to the shame that Australians should feel. Shame may not be an entirely inappropriate response to the situation, but potentially it is a debilitating response that can circumscribe public debate.

Hughes' polemical version of history asserts that 'homelands' (which, note, are never defined in the book) are the product of a socialist 'homeland' model conceived by economist Nugget Coombs. She places the main blame for ongoing disadvantage in Indigenous 'homelands' squarely on the shoulders of 'exceptionalist' self-determination policies that were implemented in such areas. This is an inadequate account of history which ignores the fact that Indigenous socioeconomic outcomes were coming from an exceptionally low base in the 1970s. Furthermore, Indigenous disadvantage was (and is) prominent in both remote and non-remote areas. Many of the policy reforms proposed by Hughes resemble the measures incorporated in the federal government's recent 'national emergency' response to child sex abuse (Altman 2007a).

My main criticism of Hughes' analysis is that she has created the space in public debate where the use of hyperbole is acceptable and, indeed, endorsed. I maintain that her earlier use of the word 'apartheid' in describing the permit and land-rights system is inappropriate and categorically wrong (Hughes 2005; Hunter 2007a). If nothing else, the debate over the NT intervention seems to indicate that the vast majority of community residents support the right to control who enters their communal property. When respected academics engage in emotional debates using rhetorical devices, then this sets a public standard whereby exaggeration and categorical errors become legitimated. The Australian has published many articles that repeat and expand on the invalid analogy of the 'Australian Apartheid'.

Curiously, the former Minister for Indigenous Affairs, Amanda Vanstone, in a 2005 speech entitled 'Beyond Conspicuous Compassion' (Vanstone 2005), had this to say:

Good intentions are not good enough. Indigenous Australians must be able to expect the same range of opportunities as other Australians. No 
more cultural museums that might make some people feel good and leave Indigenous Australians without a viable future. Continuing cultural identity does not require poverty or isolation from mainstream Australian society.

While Vanstone railed against 'conspicuous compassion', it is hard to characterise the PM and Brough's rhetoric as anything other than that. Indeed, Brough stated recently that one 'wouldn't have a soul if one did not support the blow-out in spending on the intervention'.

Ironically, it appears that some politicians (not to mention various academics and media outlets) are now competing with one another to be morally righteous and conspicuously compassionate about Indigenous child abuse. Obviously, the public are forced to tolerate the use of rhetorical devices by parliamentarians because politics is a 'blood sport', where winning the argument is more important than the substance of the issues involved. However, if the construction of effective policy is the goal, debate must include an array of less moralistic perspectives.

The only way ahead is to acknowledge the complexities of the task at hand and attempt to identify, analyse and address the most relevant issues. All involved need to be open to the possibility that their ideas are wrong, and to submit those ideas for rigorous evaluation and criticism.

\section{Preliminary Evaluations and Criticisms of NT Intervention}

The authors of the 'Little Children Are Sacred' report have been extremely critical of the legislation. For example, Pat Anderson says that there is no recommendation in their report that coincides with the legislation (Marr \& Peatling 2007). Mr Brough responded to this by saying: 'I was astounded that the report's authors provided no recommendations designed to immediately secure communities and protect children from abuse.' This accusation is more than a little unfair since a report to the NT government based on limited terms of reference cannot assume that the Commonwealth might provide additional resources to secure communities.

The other initiatives may have positive effects on community functioning, and possibly even Indigenous disadvantage, but the connections of the initiatives to child abuse have not always been demonstrated definitively. While there is considerable evidence on what needs to be done to respond to Indigenous child abuse - Radio National's The Health Report presented a summary of the evidence-based response to child abuse (Swan 2007) — the overall lack of evidence on which to link various aspects of the intervention to child abuse is a major impediment to constructing effective policy options. 
There are many possible criticisms of the legislation. Space constraints limit me to focusing on just a couple. Interested readers are referred to the transcript of the one-day Senate hearing where many of the arguments were rehearsed ${ }^{3}$ and to Altman and Hinkson (2007) who present robust criticisms of the intervention from more than 30 authors - around half of whom are Indigenous contributors.

Some of the most cogent criticism has come from a former Liberal Minister for Indigenous Affairs, Fred Chaney, in his 2007 Vincent Lingiari Lecture (2007). Indigenous people will be subject to a level of micromanagement that is unprecedented elsewhere in Australian society. Chaney highlights the suspension of the provisions of the 1975 Racial Discrimination Act and the interference in Indigenous property rights as being of particular concern. He highlights how the lack of meaningful consultation has almost guaranteed that there will be resistance (both passive and active) to the implementation of the policy.

Frank Quinlan, Executive Director of Catholic Social Services Australia, has argued that overseas evidence suggests that no beneficial outcomes flow from financial sanctions unless intensive support programs are also provided. It has also been pointed out, on the basis of evidence from US food-stamp programs, that the new welfare rules would affect only 'a small number' of families (Lane 2007). Yet the fixed costs of such interventions, such as recruiting and training case workers, and point-of-sale machines to read entitlement cards, are high (Blank 2002). Furthermore, the fixed costs of quarantining welfare payments in Australia are likely to be high (relative to the US) because of diseconomies of scale.

Linking child abuse and neglect to the welfare quarantining provisions may also have perverse consequences. Notification of abuse and neglect is often voluntary and it is possible that there will be a decline in reported child abuse and neglect if families are reluctant to suffer the social consequences of welfare/income management - even if the actual incidence of child abuse and neglect is not reduced. This is not a problem in itself, but it may have perverse consequences to the extent that support for families in need is affected.

Few commentators would argue that restricting alcohol consumption is not fundamental to tackling child abuse and dysfunctional Indigenous communities. Nevertheless, the Police Federation of Australia argues that the new liquor controls will make law enforcement difficult because there will be two competing legislative frameworks in place: the Commonwealth's new rules, and the existing Territory legislation (Hall 2007). The Federation also argues that by opening up the permit system in the larger public townships and connecting roads, law enforcement efforts to address the 'rivers of grog' will become more difficult.

3 〈www.aph.gov.au/hansard/senate/commttee/S10473.pdf〉 
Enforcement issues are critically important, as many Indigenous communities already have bans on alcohol consumption. Prohibition is especially difficult to enforce when there are non-Indigenous communities nearby with access to alcohol (that is, there is an incentive for a 'sly grog' market to develop).

Compulsory acquisition leases in townships are a direct intervention into Indigenous property rights. Legitimate questions have been raised about the just-compensation provisions for the compulsory acquisition. The changes to the permit system can also be construed as tampering with Indigenous property rights, as many communities (Oenpelli, for example) rely on the income earned from issuing permits.

As part of the intervention, Mal Brough also announced that all CDEP employment in the NT will be replaced by 'real jobs' (Altman \& Hinkson 2007: p.331). ${ }^{4}$ While some commentators question how meaningful the term 'real job' is, the major unresolved issue is where these new jobs might come from and who might finance such positions. Several NT schemes have already closed, with a concomitant loss of governance capacity for administering community-level initiatives. Brough had previously indicated that he wants the state to deliver development directly to Indigenous families and individuals, thus bypassing mediating institutions and representative structures (Altman \& Hinkson 2007: p.315). While these policy thrusts are not intrinsically inconsistent, the federal government is likely to have difficulty in developing the organisational capacity to deal directly with Indigenous people and their families - especially given the problems recently experienced in hiring and retaining Indigenous employees (Commonwealth of Australia 2006).

The most substantial criticism of the intervention is that it is an assault on Indigenous choice and, ironically, responsibility. The NT intervention is clearly paternalistic as it imposes a new set of constraints on what Indigenous people can do, both inside the welfare system and elsewhere. The intervention has been promoted on the grounds that it will assist in re-establishing norms in Indigenous communities and hence in enhancing social responsibility. In contradistinction, it has also been argued that depriving people of personal responsibility may not be the best way to increase the capacities and willingness of individuals to exercise this responsibility (Quinlan 2007).

This section has outlined some ex ante criticisms and evaluations of the NT intervention, which may or may not turn out to be valid. Given that the intervention is controversial and contestable, it is particularly important to establish a credible and accountable framework for evaluating the resulting outcomes.

\footnotetext{
4 Over the last few years, the CDEP scheme has already been scaled back in non-remote areas.
} 


\section{The Importance of Ex Post Evaluations}

One of the most disappointing aspects of the NT intervention is that there was virtually no lead time to prepare or think about an evaluation framework. Some ex ante planning with Indigenous leaders and relevant bureaucracies would have both lessened the public resistance and facilitated evaluation. It will now be very difficult to evaluate the outcomes of the intervention because no groundwork was laid to establish credible benchmarks for what existed before the policy shift.

In the United States, most major change in policy would start with a strategy for evaluating the social experiment with random assignment (Bloom 2005). Social experiments are regarded with particular suspicion in Indigenous policy because they raise ethical questions about the treatment of the Indigenous population as subjects, rather than as people. The Howard government has clearly indicated a willingness to engage in paternalism with this intervention, but its failure to establish benchmarks or construct control groups means that it will be almost impossible to attribute any changes in outcomes to the intervention. For example, the rate of child abuse and neglect in the NT may go up or down depending upon the level of measurement error both before and after the intervention. Consequently, the NT intervention is unlikely to be held to account and the government can make almost any claim it wants about what happens as a result of its policy.

Given the scale of the intervention, it would not be unreasonable to characterise it as one of the largest social experiments in Australian history with NT Indigenous communities being the 'treatment group'. Of course, the 'experiment' analogy breaks down when one remembers that there has been no attempt to randomly assign people into control and treatment groups. Another problem for the analogy is that some of the policy initiatives are not entirely confined to the NT. Nevertheless, it is time to consider explicitly adopting a more scientific approach to experiments in Indigenous affairs - especially since it is, arguably, already occurring.

One potentially important advance for the evidence on the development processes facing Indigenous children is the Longitudinal Study of Indigenous Children (LSIC). The 2007 federal budget announced that LSIC would involve around 1,500 babies and children from 11 regional sites. The relatively small sample size may circumscribe the power of the analysis to discern between competing hypotheses. Another concern is that LSIC is not national in scope and hence can be accused of reflecting regional idiosyncrasies. One potentially unfortunate side-effect of the NT intervention is that it may disproportionately affect the level of cooperation of LSIC respondents there vis-à-vis other states and territories (that is, it might induce some measure of non-sampling error). 
When LSIC data is eventually collected, it should enhance the findings from the cross-sectional studies of the Western Australian Aboriginal Child Health Survey (WAACHS, see Zubrick et al. 2006). While the proposed LSIC will not be a national study, it shares this limitation with the WAACHS.

\section{Some (Hopefully) Positive Policy Options}

Indigenous disadvantage has not arisen suddenly; rather, poor outcomes for Indigenous Australians appear to have accumulated over many generations. While the Howard government and its supporters rightly point to historical factors driving Indigenous disadvantage, their historical focus seems to be rather narrowly confined to the period between the early 1970s and the mid 1990s (for example, Hughes 2005). The quality of data was not really credible before 1981, but Census data seems to indicate that there has been steady, though not spectacular, improvement in certain socioeconomic outcomes since the 1970s (Altman, Biddle \& Hunter 2005). This seems like a counterintuitive finding but those who try to construct a narrative of failure in Indigenous policies do not contest the national statistics on which these results are based; rather, they claim that the failure is mostly manifest in remote outstations and 'homelands' (Hughes 2007). Hunter (2007a) argues that this response is inadequate as the geographic definitions used are ill-defined and, in any case, the broad changes in Indigenous wellbeing at the national level are largely reflected when a more disaggregated geography is used. This is not to say that this 'progress' is adequate, especially in the presence of substantial macroeconomic growth; rather, that the extreme claims about failure and success should be tempered.

Changes in Indigenous socioeconomic status are unlikely to be achieved without substantial commitment to providing the resources required. The long-run trend in spending on Indigenous affairs has increased over the last 30 years. From the early 1990s, Indigenous-specific expenditure as a percentage of GDP has stabilised at around one-third of one percentage point (Gardiner-Garden \& Park 2007). The per-capita measure of Indigenous-specific expenditure is complicated by uncertainty about the exact size of the Indigenous population but, given the substantial undercount of the Indigenous population (Australian Bureau of Statistics (ABS) 2007), it is entirely possible that per-capita spending has actually fallen in the last seven years. Whatever the merits of the current spending levels, it is worth asking whether funding has been spent in the most effective areas.

Indigenous policy debate is challenging at a personal level for all who attempt to engage with it. People from the left of the political spectrum need to acknowledge the existence of incentive effects and the potential for the negative influences of culture. The right will have to accept some role for 'symbolic' issues such as Indigenous rights and accept that culture and norms are more 
complex than they assume. For example, giving people a choice means having to accept that not everybody will necessarily make the same choices.

It may be naïve to think that one can separate out the politics from the policy, but complex problems need bipartisan and long-term policy options. Positive outcomes are unlikely to be achieved without the cooperation of all parties, who need to change their own (and others') behaviour(s). It should be noted that there are likely to be long lead times in changing behaviour and norms, especially in the presence of intergenerational transmission of disadvantage.

Notwithstanding the apparent lack of evidence for some of the more unique aspects of Indigenous policy, there are some things that we can do to break the 'vicious cycle' of Indigenous disadvantage and child abuse - even if we do not invoke a 'virtuous cycle' immediately. Primary among these would be to address the substance abuse and risky alcohol consumption with supply-side constraints. As argued above, some aspects of the intervention may undermine the efficacy of such policies.

Intervention into the supply of alcohol is only one policy option. Another option would be to consider a policy which operates on the demand for alcohol. If the price of alcohol were increased by raising excise taxes, this would constrain the amount of alcohol consumed in Indigenous communities (that is, if demand is not completely inelastic). This policy has the advantage that it will reduce the consumption of alcohol throughout Australia, rather than focus solely on remote Indigenous communities. ${ }^{5}$ Of course, this may be politically unpalatable, but it is important to recognise that there are many negative externalities arising from alcohol consumption for both individuals and communities throughout Australia (including non-Indigenous communities). Given that the Prime Minister has identified a national emergency, it might be considered an opportunity for a truly national policy.

Learning to drink responsibly is an important element of an Australian youth's education (Brady 2004). Social policies that support the educational process within schools and families will also play a role in addressing the widespread problem of binge drinking.

Policy also needs to facilitate positive child development through funding community infrastructure and supporting families with young children. It is important to note that supporting families does not necessarily entail increasing welfare payments, as these are likely to entail negative incentive effects that work against participation in the mainstream economy (Henry 2007). Daly and Hunter (1999) showed that many (or even most) Indigenous people would earn less than their nominal expected welfare entitlements if they secured work. The

5 Macgregor et al. (2004) propose that local Indigenous communities be allowed to set their own alcohol taxes. However, political and constitutional reality may work against any such policy. 
likely disincentive effects of welfare payments are likely to have been exacerbated by the growth of generous family payments since the late 1990s. Given that it might be politically difficult to reduce welfare payments, it is necessary to consider the issue of conditionality of welfare payments, not unlike some of the initiatives embodied in the NT intervention. Another approach worth considering is to establish a more positive set of incentives for Indigenous youth to stay at school (Hunter 2003).

Finally, it is hard to deny the historical shortfall in public investment in NT communities, especially in areas of policing and schools (Taylor \& Stanley 2005). What is needed now is a sustained effort, community consultation and partnership, effective and appropriate expenditure, and close monitoring by the media of what is being achieved (Altman 2007b). The additional commitment of resources entailed in the NT intervention aimed at ensuring security of communities is laudable, but more is needed. It is a crisis that will now require serious commitment over many years. Governments should not underestimate the magnitude of the task - Jon Altman's estimate of a \$4 billion shortfall in expenditure is extremely conservative as it only focuses on certain aspects of the policy initiatives.

\section{Learned Helplessness and Behavioural Change}

Some commentators might be surprised how uncritical many Indigenous community residents have been of the NT intervention, especially in the central desert area. There are at least two possible explanations for this. The first is that some Indigenous people are glad something is finally being done, although they may be sceptical about the efficacy of the plan (Langton 2007). Another possibility is that many Indigenous people are more used to having things done to them than being active participants in mainstream society. This second possibility underscores the major strength and weakness of the NT intervention, which involves substantial constraints on Indigenous choices, especially in the area of property rights and access to citizenship rights embodied in welfare.

Learned helplessness is a psychological condition in which a human being has learned to believe that a situation is helpless (Petersen, Maier \& Seligman 1995; Seligman 1975). The theory is that depression results from a perceived lack of control over the events in life, which may result from prior exposure to (actually or apparently) uncontrollable negative events.

Not all people become depressed as a result of being in a situation where they appear not to have control, but the intransigence of Indigenous socioeconomic circumstances is such that it would be surprising if many Indigenous people had not learned to feel helpless. Prolonged exposure to dependence on welfare is likely to be one of the major factors underlying community violence and dysfunction (Hunter 2007b). 
The top-down approach has many limitations, especially when it is attempting to change people's behaviour. One of the limitations of military-style interventions is that it perpetuates attitudes of 'learned helplessness' that need to be changed if enduring changes are to be achieved. In a sense, some aspects of the intervention will address the learned helplessness arising from the lack of mainstream employment options. However, by bundling together more controversial measures that alienate Indigenous communities and their property rights, it also risks exacerbating the feelings of alienation and helplessness.

\section{Reprise}

In summary, even if one does not disagree with some aspects of the policy focus of the NT intervention, there has been a failure to provide for adequate planning, implementation and evaluation of the initiatives. Wicked problems, in inherently complex domains such as Indigenous policy, require negotiation between stakeholders and vigorous open public debate. In some ways, the public debate has been vigorous, but many commentators have criticised the lack of transparency and openness of the public discussions. This paper emphasises the need for a bipartisan and long-term policy commitment so that substantial progress can be made in addressing Indigenous disadvantage and child abuse. While long-term commitment is essential, a transparent evaluation process is also essential to ensure that any bipartisan policy is based on solid foundations to achieve the desired outcomes.

\section{References}

ABS 2007, 'Population distribution, Aboriginal and Torres Strait Islander Australians 2006', Catalogue no. 4705.0, Canberra.

AIHW 2006, Child protection Australia 2004-05, Catalogue no. CWS 26, Canberra.

Altman, J. 2007a, 'Hughes' Homeland', Australian Book Review, September 2007, 294, pp.10-11.

Altman, J. and M. Hinkson (eds) 2007, Coercive Reconciliation: Stabilise, Normalise and Exit Aboriginal Australia, Arena, Melbourne.

Altman, J. 2007b, 'Stabilise, normalise and exit $=\$ 4$ billion', CAEPR Topical Issue No. 8/2007, CAEPR, ANU, Canberra.

Altman, J., N. Biddle and B. Hunter 2005, 'A historical perspective on Indigenous socioeconomic outcomes, 1971-2001', Australian Economic History Review, 45(3), pp.273-95.

Blank, R. 2002, 'Evaluating Welfare Reform in the United States', Journal of Economic Literature, 40(4), pp.1105-66.

Bloom, H. (ed.) 2005, Learning More from Social Experiments: Evolving Analytical Approaches, Russell Sage Foundation, New York. 
Botsman, P. 2007, 'Putting Indigenous Child Abuse in the Northern Territory into Perspective', Working Paper issued 29 June 2007 (available online at http://www.workingpapers.com.au/).

Brady, M. 2004, Indigenous Australia and Alcohol Policy. Meeting Difference with Indifference, University of New South Wales Press, Sydney.

CYI 2007, From Hand Out to Hand Up: Cape York Welfare Reform Project, Cape York Institute for Policy and Leadership, Cairns.

Chaney, F. 2007, Vincent Lingiari Lecture, presented on 11 August 2007 at Charles Darwin University, Casuarina.

Commonwealth of Australia 2006, State of the Service: 2005-06, Australian Public Service Commission, Canberra.

Conklin, J. 2003, Dialog Mapping: An Approach for Wicked Problems, Wiley, Chichester.

Daly, A. and B. Hunter 1999, 'Incentives to work: replacement ratios and the cost of job loss among unemployed Indigenous Australians', Australian Economic Review, 32(3), pp.219-36.

Gardiner-Garden, J. and M. Park 2007, 'Commonwealth Indigenous-specific expenditure 1968-2006', Background Note no. 2, 2007-08, Online only issued 8 August 2007 (http://www.aph.gov.au/library/pubs/BN/200708/08bn02.htm).

Hall, A. 2007, 'Police unhappy with NT intervention rules', $A M$, ABC, Monday, 13 August 2007 (see www.abc.net.au/am).

Henry, K. 2007, 'Creating the right incentives for Indigenous development', Address to the Cape York Institute conference, 'Strong Foundations Rebuilding Social Norms in Indigenous Communities', Cairns, 26 June 2007.

Hughes, H. 2005, 'The economics of Australian Apartheid: The causes of Indigenous deprivation', presented to the 34th Conference of Economists, held at the University of Melbourne, 26-28 September.

2007, Lands of Shame: Aboriginal and Torres Strait Islander 'Homelands' in Transition, The Centre for Independent Studies, Sydney.

Hunter, B. 2003, 'The rise of the CDEP scheme and changing factors underlying Indigenous male employment', Australian Journal of Labour Economics, 6(3), pp.473-96.

2006, 'Further Skirmishes in the Poverty War: Income Status and financial stress among Indigenous Australians', Australian Journal of Labour Economics, 9(1), pp.51-64. 
2007a, 'Arguing over [the] remote control: Why Indigenous policy needs to be based on evidence and not hyperbole', Economic Papers, 26(1), pp.44-63.

2007b, 'Cumulative Causation and the Productivity Commission's Framework for Overcoming Indigenous Disadvantage?' presented at the Australian Social Policy Conference 'Social Policy through the Life Course: Building Community Capacity and Social Resilience', University of New South Wales, Sydney, 11-13 July 2007.

Lane, B. 2007, 'Welfare sticks cost many carrots', The Australian, 8 August 2007.

Langton, M. 2007, 'Alcohol-induced violence: The effects of grog on social norms in communities', Address to the Cape York Institute conference, 'Strong Foundations - Rebuilding Social Norms in Indigenous Communities', Cairns, 26 June 2007.

Macgregor, D. et al. 2004, Imagining Australia: Ideas For Our Future, Allen \& Unwin, Sydney.

Marr, D. and S. Peatling 2007, 'Entering dangerous territory: Everyone is tarred with the same brush under John Howard's Emergency Response legislation', Sydney Morning Herald, 11 August 2007.

Martin, D. 1988, 'Background Paper on Social and Family Factors for the Arukun Case', Report to the Royal Commission into Aboriginal Deaths in Custody, Department of Prehistory and Anthropology, ANU, Canberra.

Memmott, P. et al. 2001, Violence in Indigenous Communities, Crime Prevention Branch, Attorney General's Department, Canberra.

Pearson, N. 2007, 'Politics aside, an end to the tears is our priority', The Australian, 23 June 2007.

Petersen, C., S. Maier and M. Seligman 1995, Learned Helplessness: A Theory for the Age of Personal Control, Oxford University Press, New York.

Quinlan, F. 2007, 'Submission to Senate Legal and Constitutional Affairs Committee, Inquiry into the Provisions of the Northern Territory Emergency Response Bill 2007 and Associated Bills', Catholic Social Services Australia, Canberra.

Rittel, H. and M. Webber 1973, 'Dilemmas in a general theory of planning', Policy Sciences, 4(2), pp.155-69.

Sanders, W. 2007, 'In the name of failure: The Howard government's generational revolution in Indigenous affairs', presented in the CAEPR seminar series, ANU, Canberra.

Seligman, M. 1975, Helplessness: On Depression, Development and Death, W. H. Freeman, San Francisco. 
Swan, N. 2007, 'Little children are sacred. What's an evidence-based response?' The Health Report, ABC Radio National, 2 July 2007.

Taylor, J. and O. Stanley 2005, 'The opportunity costs of the status quo in the Thamarrurr Region', CAEPR Working Paper No. 28, CAEPR, ANU, Canberra.

Vanstone, A. 2005, 'BEYOND CONSPICUOUS COMPASSION: Indigenous Australians Deserve More Than Good Intentions', address to Australia and New Zealand School of Government, ANU, Canberra, 7 December.

Wild, R. and P. Anderson 2007, Ampe Akelyernemane Meke Mekarle, Report to the Northern Territory Government, Darwin.

Zubrick, S. et al. 2006, 'The Western Australian Aboriginal Child Health Survey: Strengthening the Capacity of Aboriginal Children, Families and Communities', Curtin University of Technology and Telethon Institute for Child Health Research, Perth.

Thanks are due to Jon Altman and three anonymous referees for detailed and insightful comments. 